\title{
Role of Histopathological Differentiation as a Prognostic Factor for Treatment Response in Locally Advanced Squamous Cell Carcinoma Cervix Patients
}

\begin{abstract}
Introduction: The aim of the study was to evaluate the prognostic significance of histopathological differentiation in treatment outcome of locally advanced carcinoma cervix. Materials and Methods: This retrospective study includes 167 patients of locally advanced carcinoma cervix treated between January 2006 and December 2008 who have received definitive chemoradiation. Results: The number of patients with well $(85[50.9 \%])$ and moderately differentiated (76 [45.5\%]) carcinoma was nearly equal with poorly differentiated variety having only $6(3.6 \%)$ patients. On completion of treatment out of the 167 patients, $133(79.6 \%)$ had a complete response and $34(20.4 \%)$ had residual disease. On mean follow-up of 11 months, 19 (14.2\%) patients had local and $5(3.7 \%)$ had a distant relapse. Histopathological differentiation and age had no association with treatment outcome, whereas early-stage disease showed trend favoring better treatment response. Conclusion: Advanced stage along with poor histopathological differentiation influences the aggressiveness of the tumor responsible for distant relapse. However, histopathological differentiation has no correlation with local treatment response and overall survival. The main factor influencing the treatment outcome is the intrinsic radiosensitivity of the tumor and volume of the disease.
\end{abstract}

Keywords: Carcinoma cervix, histopathological differentiation, intrinsic radiosensitivity, prognostic factor, treatment outcome

\section{Introduction}

Carcinoma cervix is the most common malignancy in women in the developing nation including India. ${ }^{[1]}$ Various treatment modalities such as radiotherapy and chemoradiotherapy have been used to improve the outcome, but the results remain unsatisfactory. ${ }^{[2,3]}$ The role of human papillomavirus and other risk factors in the pathogenesis of cancer cervix have been well documented, but the prognostic factors which determine the treatment outcome in these patients have been elusive. ${ }^{[4]}$

Numerous tumor and patient factors have been studied for potential prognostic value. Depth of invasion, tumor size, lymphovascular invasion, tumor hypoxia, International Federation of Gynecologists and Oncologists (FIGO) staging, treatment response, and lymph node metastasis are well-established prognostic factors. ${ }^{[5,6]}$ Age, race, histopathological grading, apoptosis, and radiation response markers are other prognostic factors which are controversial. ${ }^{[7-9]}$

This is an open access journal, and articles are distributed under the terms of the Creative Commons Attribution-Non Commercial-ShareAlike 4.0 License, which allows others to remix, tweak, and build upon the work non-commercially, as long as appropriate credit is given and the new creations are licensed under the identical terms.

For reprints contact: reprints@medknow.com
Squamous cell carcinoma is the most common histology seen in patients with carcinoma cervix; it is further differentiated into well-differentiated (WD), moderately differentiated (MD), and poorly differentiated (PD) depending on the degree of differentiation. Around 50\%-60\% of squamous cell carcinomas are $\mathrm{MD}$, $30 \%-40 \%$ are WD, and only $5 \%-10 \%$ are PD. Tumor differentiation is the result of the accumulation of multiple mutations, with PD tumors having most mutations as compared to WD and MD tumors. The malignant features such as rapid tumor growth, invasiveness, and metastatic potential are more in less differentiated forms of squamous cell carcinoma; hence, less differentiated tumors represent an aggressive variety of squamous cell carcinoma as compared to more differentiated counterparts. ${ }^{[10]}$

We have undertaken this study to observe the possible impact of degree of differentiation which governs the aggressiveness of tumor on treatment response in patients of squamous cell carcinoma cervix.

\footnotetext{
How to cite this article: Shah A, Jena NK, Shukla P. Role of histopathological differentiation as a prognostic factor for treatment response in locally advanced squamous cell carcinoma cervix patients. Indian J Med Paediatr Oncol 2018;39:282-6.
}

\section{Afsana Shah, Nihar Kanta Jena, Pragya Shukla}

Department of Radiation Oncology, Delhi State Cancer Institutes, New Delhi, India

\author{
Address for correspondence: \\ Dr. Pragya Shukla, \\ Department of Radiation \\ Oncology, Delhi State Cancer \\ Institutes, East Dilshad Garden, \\ New Delhi - 110 095, India. \\ Email:pragyaonco@gmail.com
}

Access this article online

Website: www.ijmpo.org

DOI: 10.4103/ijmpo.ijmpo_152_16

Quick Response Code:

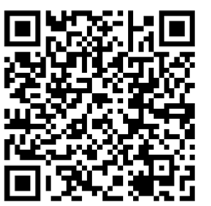




\section{Materials and Methods}

A retrospective analysis of records of patients with locally advanced nonmetastatic carcinoma cervix (Stage II and above), with squamous cell carcinoma histology, and whose differentiation was available and treated with radical radiotherapy between January 2006 and December 2008 was done. A total of 167 patients who had completed the prescribed dose were only included and treatment-defaulter patients were excluded from the study. Tumors were graded as $\mathrm{WD}, \mathrm{MD}$, and $\mathrm{PD}$ depending on the degree of keratin pearl formation, keratinization, and overall resemblance of carcinoma to normal squamous epithelium. ${ }^{[1]}$ All patients received external beam radiotherapy, 50 Gy in 25 fractions, by 4 fields or 2 fields depending on separation, was delivered using cobalt-60 unit with $80 \mathrm{~cm}$ solid-state drive. All patients received weekly cisplatin $35 \mathrm{mg} / \mathrm{m}^{2}$ by slow IV infusion in $2 \mathrm{~h}$ with appropriate hydration. Chemotherapy was stopped whenever there was persistent vomiting despite antiemetics, derangement of renal function, Grade 3 leukopenia, or in case of noncompliance.

It was followed by high dose-rate brachytherapy 18 Gy in 2-3 fractions at 1 week interval using Fletcher-Suit afterloading applicators. Those patients, who were not suitable for intracavitary radiotherapy, received supplementary radiation therapy by two lateral fields to a total dose of $66 \mathrm{~Gy}$.

Patients were staged according to the FIGO staging system, after a workup, which included clinical examination, hemogram, kidney function tests, chest X-ray, intravenous pyelography, cystoscopy, and rectosigmoidoscopy. Ultrasound abdomen and computed tomography scans of abdomen were also done at the discretion of the physician.

\section{Results}

Patients' characteristics have been given in Table 1.

Age of patients ranged from 30 to 75 years with a mean value of $49.74 \pm 11.19$ years, $80(47.9 \%)$ patients had Stage II and 87 (52.1\%) had Stage III disease. All the patients had squamous cell histology with 85 (50.9\%) having WD, 76 (45.5\%) MD, and 6 (3.6\%) PD histopathology.

Demographic Associations have been given in Table 2.

Majority of subjects $(51.4 \%)$ aged $<60$ years were found to be having WD while those aged $>60$ years were observed to be having MD histopathology (52\%), but no significant association between age and histopathological differentiation was observed $(P=0.502)$. No significant association between stage and histopathological differentiation was also observed $(P=0.289)$.

Treatment outcome has been given in Table 3.

Of the 167 patients treated, $133(79.6 \%)$ had a complete response and $34(20.4 \%)$ had residual disease. Nineteen patients developed local recurrence and five patients had a distant relapse in a median follow-up of 11 months. The pattern of residual and recurrences cases is shown in the Tables 4 and 5. The distant relapse in PD group was seen in two patients out of six (33.3\%) as compared with WD group which was seen in 1 out of $85(1.17 \%)$ patients and MD group which was seen in 2 out of $76(2.63 \%)$ which was significantly more, $P=0.025$ (Fisher's exact test) and $P=0.011$ (Fisher's exact test), respectively, and among patients with Stage III disease, 4 out of 87 (4.6\%) developed distant relapse, whereas in Stage II, only 1 out of $80(1.25 \%)$ had distant relapse. Local recurrence in MD group 9/76 (11.84\%) and WD group $10 / 85(11.75 \%)$ is similar, but local recurrence in

\begin{tabular}{lc}
\hline \multicolumn{2}{c}{$\begin{array}{c}\text { Table 1: Distribution of patients with respect to age, } \\
\text { stage, and histopathological differentiation }\end{array}$} \\
\hline \multicolumn{2}{c}{$\boldsymbol{n ( \% )}$} \\
\hline Age (years) \\
$\leq 60$ & $142(85)$ \\
$>60$ & $25(15)$ \\
Stage & \\
Stage II & $80(47.9)$ \\
Stage III & $87(52.1)$ \\
Differentiation & \\
Well & $85(50.9)$ \\
Moderately & $76(45.5)$ \\
Poorly & $6(3.6)$ \\
\hline
\end{tabular}

\begin{tabular}{|c|c|c|}
\hline \multirow[t]{2}{*}{ HPE differentiation } & \multicolumn{2}{|c|}{ Age and HPE differentiation } \\
\hline & $\begin{array}{c}\leq 60 \text { years } \\
(n=142), n(\%)\end{array}$ & $\begin{array}{c}>60 \text { years } \\
(n=25), n(\%)\end{array}$ \\
\hline Poorly differentiated & $6(4.23)$ & $0(0.00)$ \\
\hline Moderately differentiated & $63(44.37)$ & $13(52.00)$ \\
\hline Well differentiated & $73(51.41)$ & $12(48.00)$ \\
\hline$\chi^{2} ; \mathrm{df} ; P$ & 1.377; & .502 \\
\hline \multirow[t]{2}{*}{ HPE differentiation } & \multicolumn{2}{|c|}{ Stage and HPE differentiation } \\
\hline & $\begin{array}{c}\text { Stage II }(n=80) \text {, } \\
n(\%)\end{array}$ & $\begin{array}{c}\text { Stage III } \\
(n=87), n(\%)\end{array}$ \\
\hline Poorly differentiated & $1(1.25)$ & $5(5.75)$ \\
\hline Moderately differentiated & $38(47.50)$ & $38(43.68)$ \\
\hline Well differentiated & $41(51.25)$ & $44(50.57)$ \\
\hline$\chi^{2} ; \mathrm{df} ; P$ & \multicolumn{2}{|c|}{$2.483 ; 2 ; 0.289$} \\
\hline
\end{tabular}

HPE - Histopathological examination

Table 3: Treatment outcome of the patients after receiving radical chemo-radiotherapy with median follow-up of 11 months

\begin{tabular}{lc}
\hline Outcome & Number of subjects (\%) \\
\hline Complete response & $133(79.6)$ \\
Residual disease & $34(20.4)$ \\
Local recurrence & $19(14.7)$ \\
Distant relapse & $5(3.75)$ \\
\hline
\end{tabular}




\begin{tabular}{llcccc}
\hline \multicolumn{5}{c}{ Table 4: Comparing the residual pattern of disease with respect to stage and histopathological differentiation } \\
\hline Stage & Posttreatment status & Poorly differentiated & Moderately differentiated (\%) & Well differentiated (\%) & Total \\
\hline Stage II & No disease & 1 & $34(89.5)$ & $33(80.5)$ & 67 \\
& Residual & 0 & $4(10.5)$ & $9(19.5)$ & 12 \\
& Total & 1 & 38 & 41 & 80 \\
\multirow{2}{*}{ Stage III } & No disease & 4 & $28(73.7)$ & $33(75.0)$ & 61 \\
& Residual & 1 & $10(26.3)$ & $10(25)$ & 21 \\
& Total & 5 & 38 & 44 & 87 \\
\hline
\end{tabular}

\begin{tabular}{llcccc}
\hline \multicolumn{2}{c}{ Table 5: Comparing the recurrence pattern of disease with respect to stage and histopathological differentiation } \\
\hline Stage & Recurrence & Poorly differentiated & Moderately differentiation & Well differentiated & Total \\
\hline Stage II & Local & 0 & 3 & 3 & 6 \\
\multirow{2}{*}{ Stage III } & Distant & 0 & 1 & 7 & 1 \\
& Local & 0 & 6 & 1 & 13 \\
\multirow{2}{*}{ Total } & Distant & 2 & 1 & 11 & 4 \\
\hline
\end{tabular}

Stage III disease (13/87 [14.95\%]) is twice that of Stage II $6 / 80(7.5 \%)$.

Treatment outcome association with age, stage, and histopathologic grading has been given in Table 6 .

Treatment outcome in relation to age, stage, and histopathological examination has shown no statistically significant relation; however, Stage II patients have better treatment response as compared to Stage III patients $(P=0.099)$.

On multivariate analysis, only one subgroup of patients who are $<60$ years and Stage II have shown better treatment response in MD variety [Table 7].

\section{Discussion}

The value of histopathological differentiation as a prognostic factor for treatment response is controversial. Hardt et al., ${ }^{[12]}$ in his study observed that there was a lower incidence of complete response to radiation in keratinizing squamous cell cancers (WD) than in large cell nonkeratinizing squamous cell carcinoma, thus concluding that better differentiated forms of squamous cell carcinoma histology have poor treatment response, but no other study has found similar association. In our study, we found no association between histological differentiation and treatment response. Even studies done on head and neck squamous cell carcinoma have shown no relation between differentiation and treatment response. ${ }^{[13]}$

The relapse pattern in our study showed that distant relapse is more common in $\mathrm{PD}$ group as compared with that of WD and MD groups in Stage III as compared to Stage II, showing that less differentiated tumors and advanced stage are more aggressive, similar results were observed in head-and-neck squamous cell carcinoma where PD variety and advanced stage were more prone to nodal metastasis as compared to better differentiated forms. ${ }^{[13]}$ Local recurrence is dependent on stage of the

\begin{tabular}{|c|c|c|}
\hline \multicolumn{3}{|c|}{$\begin{array}{l}\text { Table 6: Association of treatment response with stage of } \\
\text { the disease, histopathological differentiation, and age of } \\
\text { patients }\end{array}$} \\
\hline \multirow[t]{2}{*}{ HPE differentiation } & \multicolumn{2}{|c|}{$\begin{array}{c}\text { HPE differentiation and treatment } \\
\text { response }\end{array}$} \\
\hline & $\begin{array}{c}\text { No disease } \\
(n=133), n(\%)\end{array}$ & $\begin{array}{c}\text { Residual } \\
(n=34), n(\%)\end{array}$ \\
\hline Poorly differentiated & $5(83.33)$ & $1(16.67)$ \\
\hline Moderately differentiated & $62(81.58)$ & $14(18.42)$ \\
\hline Well differentiated & $66(77.65)$ & $19(22.35)$ \\
\hline$\chi^{2} ; \mathrm{df} ; P$ & \multicolumn{2}{|c|}{$0.435 ; 2 ; 0.805$} \\
\hline \multirow[t]{2}{*}{ Age (years) } & \multicolumn{2}{|c|}{ Age and treatment response } \\
\hline & No disease $(n=133)$ & Residual $(n=34)$ \\
\hline$<60$ & $114(80.28)$ & $28(19.72)$ \\
\hline$>60$ & $19(76.00)$ & $6(24.00)$ \\
\hline$\chi^{2} ; \mathrm{df} ; P$ & \multicolumn{2}{|c|}{$0.240 ; 1 ; 0.624$} \\
\hline \multirow[t]{2}{*}{ Stage } & \multicolumn{2}{|c|}{ Stage and treatment response } \\
\hline & No disease $(n=133)$ & Residual $(n=34)$ \\
\hline 11 & $68(85)$ & $12(15)$ \\
\hline III & $65(74.7)$ & $22(25.3)$ \\
\hline$\chi^{2} ; \mathrm{df} ; P$ & \multicolumn{2}{|c|}{$2.720 ; 1 ; 0.099$} \\
\hline
\end{tabular}

HPE - Histopathological examination

disease (Stage III $14.95 \%$ vs. Stage II $7.5 \%$ ) and not on histopathological differentiation (MD group $11.84 \%$ vs. WD $11.75 \%$ ).

Histopathological differentiation influencing survival in squamous cell carcinoma in either cervix or head and neck is not established even though some studies have found some correlation. ${ }^{[13-15]}$ Our study too found no correlation between differentiation and survival.

From the facts of radiobiology, it is known that radiosensitivity of squamous cell carcinoma has bell-shaped curve, which ranges from extremely radiosensitive to extremely radioresistant, so the main factor responsible for treatment response seems to be intrinsic radiosensitivity of the tumor cell. ${ }^{[16]}$ In vitro studies have shown intrinsic 


\begin{tabular}{|c|c|c|c|}
\hline \multirow[t]{2}{*}{ Age group } & \multicolumn{2}{|c|}{ Histopathological differentiation } & \multirow[t]{2}{*}{ Total } \\
\hline & $\begin{array}{c}\text { Moderately } \\
\text { differentiated }(\%)\end{array}$ & $\begin{array}{c}\text { Well } \\
\text { differentiated }(\%)\end{array}$ & \\
\hline \multicolumn{4}{|l|}{ Stage II } \\
\hline \multicolumn{4}{|l|}{$<60$ years } \\
\hline No disease & $30(93.8)$ & $27(77.1)$ & 57 \\
\hline Residual & $2(6.2)$ & $9(22.9)$ & 11 \\
\hline Total & 32 & 36 & 68 \\
\hline $\begin{array}{l}\chi^{2} ; P \\
>60 \text { years }\end{array}$ & \multicolumn{3}{|c|}{$3.631 ; 0.057$} \\
\hline No disease & $4(66.7)$ & $6(100)$ & 10 \\
\hline Residual & $2(33.3)$ & 0 & 2 \\
\hline Total & 6 & 6 & 12 \\
\hline$\chi^{2} ; P$ & \multicolumn{3}{|c|}{$2.400 ; 0.121$} \\
\hline \multicolumn{4}{|l|}{ Stage III } \\
\hline No disease & $23(74.2)$ & $29(76.3)$ & 52 \\
\hline Residual & $8(25.8)$ & $8(23.7)$ & 16 \\
\hline Total & 31 & 37 & 68 \\
\hline $\begin{array}{l}\chi^{2} ; P \\
>60 \text { years }\end{array}$ & \multicolumn{3}{|c|}{$0.041 ; 0.839$} \\
\hline No disease & $5(71.4)$ & $4(66.7)$ & 9 \\
\hline Residual & $2(28.6)$ & $2(33.3)$ & 4 \\
\hline Total & 7 & 6 & 13 \\
\hline$\chi^{2} ; P$ & \multicolumn{3}{|c|}{$0.034 ; 0.853$} \\
\hline
\end{tabular}

radiosensitivity of cervix tumors to be independent of disease stage, tumor differentiation, and patient age. However, increased tumor radioresistance for large volume disease has been observed probably due to the presence of hypoxic region in the tumor of large volume disease. ${ }^{[16,17]}$

Patients with advanced cancer (Stage III and IVA) have poor treatment response. ${ }^{[12,18,19]}$ In our study also, a trend toward a better response in Stage II as compared to Stage III was seen $(P=0.099)$, but no significant difference was seen probably because most of our Stage II patients had bulky disease $(>4 \mathrm{~cm})$.

Age as a prognostic factor for overall treatment outcome of carcinoma cervix is very controversial. Two European studies $^{[7]}$ have shown a better response in younger age whereas others have shown a better response in older patients. ${ }^{[12,18]}$ Eighty-five percent of our patients were $<60$ years, and we found no association of age and treatment response, but on subgroup analysis patients with early stage and younger age have better treatment response in MD variety but no such correlation was seen in either WD or PD groups, which could be explained by a relatively larger sample size in $<60$ years group.

We observed that histopathological differentiation and age have no association with treatment response but stage and volume of the disease do influence the treatment outcome.
Intrinsic radiosensitivity of the tumor is an important factor which determines the treatment outcome. Histopathological differentiation does influence the aggressiveness of the disease with PD tumors being more aggressive than better-differentiated forms.

\section{Conclusion}

Advanced stage along with poor histopathological differentiation influences the aggressiveness of the tumor responsible for distant relapse. However, histopathological differentiation has no correlation with local treatment response and overall survival. The other factor influencing the treatment outcome is the intrinsic radiosensitivity of the tumor and volume of the disease, mainly responsible for local control. Intrinsic radiosensitivity of the tumor, which most likely governed by molecular characteristic of the tumor. This work lays the groundwork for identifying the molecular characteristics of differently differentiated tumors as predictive markers of radiation sensitivity and responsiveness.

Financial support and sponsorship

Nil.

\section{Conflicts of interest}

There are no conflicts of interest.

\section{References}

1. Ferlay J, Shin HR, Bray F, Forman D, Mathers C, Parkin DM. GLOBOCAN 2008 v1.2, Cancer Incidence and Mortality Worldwide: IARC CancerBase No. 10 [internet]. Lyon, France: International Agency for Research on Cancer, 2010. Available form: http://globocan.iarc.fr.

2. Brady LW, Plenk HP, Hanley JA, Glassburn JR, Kramer S, Parker RG, et al. Hyperbaric oxygen therapy for carcinoma of the cervix - Stages IIB, IIIA, IIIB and IVA: Results of a randomized study by the radiation therapy oncology group. Int $\mathrm{J}$ Radiat Oncol Biol Phys 1981;7:991-8.

3. Hornback NB, Shupe RF, Shidnia H, Marshall RN, Tamara Lauer RN. Advanced stage $3 \mathrm{~B}$ cancer of the cervix treatment by hyperthermia and radiation. Gynecol Oncol 1986;23:160-7.

4. Bosch FX, Lorincz A, Muñoz N, Meijer CJ, Shah KV. The causal relation between human papillomavirus and cervical cancer. J Clin Pathol 2002;55:244-65.

5. Sevin BU, Nadji M, Lampe B, Lu Y, Hilsenbeck S, Koechli OR, et al. Prognostic factors of early stage cervical cancer treated by radical hysterectomy. Cancer 1995;76:1978-86.

6. Kamura T, Tsukamoto N, Tsuruchi N, Saito T, Matsuyama T, Akazawa $\mathrm{K}$, et al. Multivariate analysis of the histopathologic prognostic factors of cervical cancer in patients undergoing radical hysterectomy. Cancer 1992;69:181-6.

7. Meanwell CA, Kelly KA, Wilson S, Roginski C, Woodman C, Griffiths R, et al. Young age as a prognostic factor in cervical cancer: Analysis of population based data from 10,022 cases. $\mathrm{Br}$ Med J (Clin Res Ed) 1988;296:386-91.

8. Wheeler JA, Stephens LC, Tornos C, Eifel PJ, Ang KK, Milas L, et al. ASTRO Research Fellowship: Apoptosis as a predictor of tumor response to radiation in Stage IB cervical carcinoma. 
American Society for Therapeutic Radiology and Oncology. Int J Radiat Oncol Biol Phys 1995;32:1487-93.

9. Haensgen G, Krause U, Becker A, Stadler P, Lautenschlaeger C, Wohlrab W, et al. Tumor hypoxia, p53, and prognosis in cervical cancers. Int J Radiat Oncol Biol Phys 2001;50:865-72.

10. Hanahan D, Weinberg RA. The hallmarks of cancer. Cell 2000;100:57-70.

11. World Health Organization. International Histological Classification of Tumors. Vol. 1-25. Geneva: World Health Organization; 1978.

12. Hardt N, van Nagell JR, Hanson M, Donaldson E, Yoneda J, Maruyama $\mathrm{Y}$, et al. Radiation-induced tumor regression as a prognostic factor in patients with invasive cervical cancer. Cancer 1982;49:35-9.

13. Janot F, Klijanienko J, Russo A, Mamet JP, de Braud F, El-Naggar AK, et al. Prognostic value of clinicopathological parameters in head and neck squamous cell carcinoma: A prospective analysis. Br J Cancer 1996;73:531-8.
14. Reagan JW, Fu YS. Histologic types and prognosis of cancers of the uterine cervix. Int J Radiat Oncol Biol Phys 1979;5:1015-20.

15. Crissman JD, Budhraja M, Aron BS, Cummings G. Histopathologic prognostic factors in stage II and III squamous cell carcinoma of the uterine cervix. An evaluation of 91 patients treated primarily with radiation therapy. Int J Gynecol Pathol 1987;6:97-103.

16. West CM, Davidson SE, Burt PA, Hunter RD. The intrinsic radiosensitivity of cervical carcinoma: Correlations with clinical data. Int J Radiat Oncol Biol Phys 1995;31:841-6.

17. West CM, Davidson SE, Roberts SA, Hunter RD. Intrinsic radiosensitivity and prediction of patient response to radiotherapy for carcinoma of the cervix. Br J Cancer 1993;68:819-23.

18. Hong JH, Chen MS, Lin FJ, Tang SG. Prognostic assessment of tumor regression after external irradiation for cervical cancer. Int J Radiat Oncol Biol Phys 1992;22:913-7.

19. Marcial VA, Bosch A. Radiation-induced tumor regression in carcinoma of the uterine cervix: Prognostic significance. Am J Roentgenol Radium Ther Nucl Med 1970;108:113-23. 